\title{
A Study on the Development and Application of Patellofemoral Joint Radiography Auxiliary Device for Tangential Axial Radiography of the Patellar and Patellofemoral Joints
}

\section{Do-Byung Rhee}

Catholic University of Daegu https://orcid.org/0000-0001-7474-9127

Hee-June Kim

Kyungpook National University Hospital

\section{Deok-Mun Kwon}

Daegu Health College

Jung-Su Kim

Daegu Health College

Hyun-Woo Choi

Kyungpook National University School of Medicine

Jong-Ki Kim ( $\square$ jkkim@cu.ac.kr)

Catholic University of Daegu School of Medicine

\section{Research Article}

Keywords: patellar, patellofemoral joints, Settegast, Hughston, Laurin, Merchant

Posted Date: September 13th, 2021

DOI: https://doi.org/10.21203/rs.3.rs-869658/v1

License: (a) (i) This work is licensed under a Creative Commons Attribution 4.0 International License. Read Full License

Version of Record: A version of this preprint was published at Applied Bionics and Biomechanics on October 12th, 2022. See the published version at https://doi.org/10.1155/2022/5951285. 


\section{Abstract}

This study evaluated the accuracy of tangential axial radiography of the patellofemoral joints using an auxiliary device, which we named patellofemoral joint radiography (PJR). To compare the PJR and conventional radiography methods such as the Laurin, Merchant, and Settegast, the images taken by three methods were evaluated using a whole body phantom (PBU-31). Settegast was the radiographic method that had the smallest inclination of the patella and showed the best half lateral image of the patella, with a difference of $5.76 \%$ when compared with PJR $(p=0.001)$. PJR was the method that had the largest distance between the patellar and femoral joint spaces, with a difference of $14.54 \%$ when compared with the Merchant method $(p=0.001)$. PJR was the method in which the two bones were well overlapped (i.e., measured by the distance between the femoral trochlear groove and the tibial tuberosity), with a difference of $109.41 \%$ when compared with the Merchant method $(p=0.001)$. The Settegast method has the image with the smallest inclination of the patella, but the PJR has the image that best describes the patellofemoral joint and the least distortion of the image. when using PJR, bending the knee by $40^{\circ}$ degree and setting a $140^{\circ}$ angle between the long axis of the femur and the long axis of the lower leg were considered to be the most beneficial conditions. We propose the use of PJR for tangential axial radiography of the patellar and patellofemoral joints.

\section{Introduction}

In general, knee pain is caused by an imbalance in the patellar tracking control during knee flexion and extension [1]. If the structures that cause the patella to travel past the femoral trochlear groove are not in balance when the knee joint is extended, friction occurs on the patellar surface and prevents proper movement of the patella; in severe cases, this may cause dislocation. The stress generated by this abnormal movement route causes pain in the patellofemoral joint [2]. Examinations of the patellofemoral joint are diverse and include physical examination, radiography, CT, MRI, and arthroscopy. Among these, visual examination and radiography are the primary tests that are mainly performed to diagnose problems, such as patellar fracture, dislocation, and subluxation and knee joint varus, valgus, and malalignment. There are several radiographic methods to assess various diseases of the patellofemoral joint. Patellofemoral joint tangential axial radiography and intercondyloid fossa radiography are mainly performed $[3,4]$. Tangential axial radiography is advantageous for evaluating wear on the patellofemoral joint surface, identifying the half lateral image of the patella, and understanding the relationship between the femur and tibia. Moreover, it is an important radiographic method for determining patellofemoral joint structure, shape, and damage [5]. Existing radiography methods have caused distinct problems. The Settegast and Hughston methods perform radiography in prone knee bending position. This method cannot be used to patients with knee flexion contracture or patellar fractures and dislocations. The Laurin method performs radiography by bending the knee in a sitting position. since a patient must directly hold the detector (image receptor) in a sitting position and perform radiographic imaging, there is a risk of shaking and falling from an unstable position When performing radiographs by Merchant method, the legs should be placed in the Merchant-specific auxiliary device in the supine position. Both knees should be radiographed twice each, and the position of the femur should be kept horizontal on the examination 
table. Therefore, the authors of this study developed a patellofemoral joint radiography (PJR) auxiliary device (Fig. 1) to directly solve the problems encountered during conventional imaging. The biggest advantage of the PJR method is that a patient can fine-tune the angle of the knee after putting the leg into an auxiliary device in the supine position. The purpose of this study was to compare the PJR method with conventional radiographic methods for tangential axial radiography of the patellofemoral joints. In addition, radiographic evaluation items were set and used to compare radiographic images and determine the most suitable among the radiographic methods.

\section{Materials And Methods}

\subsection{Experimental equipment}

The X-ray imaging equipment used in this study was the Digital Radiography X-ray System (Innovision-SH 3D; DK Healthcare Co.). For the wireless detector type, a mobile flat panel detector [FXRD-1417NAW model (CsI)] was used. The left leg, including the patellar and patellofemoral joints, of the whole body phantom (PBU-31, Kyoto Kahaku Inc., Japan) was used.

\subsection{Experimental methods}

Using PJR, the phantom knee was bent at $70^{\circ}$ to $20^{\circ}$ by varying the angle at $10^{\circ}$ intervals, and the long axes of the femur and lower leg were set at $110^{\circ}$ to $160^{\circ}$. At this time, the angles of the X-ray tube and detector were positioned to remain perpendicular to the angle of the patella with every change in during knee bend at $10^{\circ}$ (Figs. 2 and 3a). Each of the six radiography methods collected 30 images, and a total of 180 images were compared and analyzed. The Houston method is advantageous for patients who cannot bend the knee less than $45^{\circ}$ to $55^{\circ}$, but it has a large disadvantage of causing distortion in the radiographic image. Radiography in the prone position was performed only by the Settegast method, in which the X-ray tube was set at an angle of $15^{\circ}$ toward the patella by bending the phantom's knee to $105^{\circ}$ (Fig. 3b) [6-9]. 30 settegast images were collected. The Laurin method is a condition in which the knee is bent by $20^{\circ}$ and the long axis of the femur and the long axis of the tibia and fibula are set at an angle of $160^{\circ}$ (Fig. 3c) [10, 11]. 30 Laurin images were collected. The Laurin method is contained within the method using PJR. With the Merchant method, the knee was bent at $45^{\circ}$, each leg was placed in a Merchant-specific assist device, the detector was positioned about $30 \mathrm{~cm}$ below the knee, and the X-ray tube was positioned at an angle of $30^{\circ}$ toward the patella (Fig. 3d) [12]. 30 Merchant images were collected. The following radiographic settings were the same for all methods: $55 \mathrm{kV}, 250 \mathrm{~mA}, 0.045$ seconds of exposure time, and a source to image receptor distance (SID) of $110 \mathrm{~cm}$ (Fig. 4). The radiographic evaluation items were:

a) the distance between the line connecting the medial and lateral sides of the patella and the lowest point of the median ridge of the patella (DMLP), which was measured to evaluate patellar inclination. The smaller the DMLP measurement result, the better.

b) the patellofemoral joint space distance (DPFG). The larger the DPFG measurement result, the better. 
c) the distance between the femoral trochlear groove and the tibial tuberosity (DFGT), which was measured to evaluate the degree of overlap between the two bones. As a result of DFGT measurement, values near the number 0 are superior (Fig. 5).

\subsection{Statistical analysis}

The quantitative values of the radiographic images were measured and evaluated using a Picture Archiving Communication System program (Centricity, GE healthcare, Chicago, IL, USA). For each measured variable, statistical significance was verified by one-way ANOVA using the Statistical Package for the Social Sciences software (SPSS 20.0, IBM SPSS Statistics, Chicago, IL, USA). Using the PJR, the phantom's knee flexion was changed six times at $10^{\circ}$ intervals to find the most appropriate radiographic conditions among the measured values, which were then compares with those by the Laurin, Merchant, and Settegast methods using one-way ANOVA. The statistical significance level was set to $p<0.05$.

\section{Results}

\subsection{Phantom experiment using the PJR}

In all experiments, the $\mathrm{X}$-ray tube angle and detector angle settings were made perpendicular to the patellar angle. A summary of the measurement results are shown in Table 1 and Fig. 6a. The following were the findings with each change in the angle of the phantom's knee for six times at $10^{\circ}$ intervals using PJR: a) the smallest inclination of the patella based on DMLP evaluation was when the knee was bend at a $20^{\circ}$ degree angle, the angle between the long axis of the femur and the lower leg was $160^{\circ}$; this was the same method as the Laurin method; $b$ ) the largest patellofemoral joint spacing based on DPFG evaluation was when the knee was bend at a 40 degree, the angle between the long axis of the femur and the lower leg was $140^{\circ}$; and $\mathrm{c}$ ) the most consistent value for the distance between the femoral trochlear groove and the tibial tuberosity based on the DFGT evaluation was when the knee was bend at a 40 degree, the angle between the long axis of the femur and the lower leg was $140^{\circ}$. 
Table 1

Results of taking radiographic images at $160^{\circ}$ to $110^{\circ}$ by changing the knee flexion angle at $10^{\circ}$ intervals using Development of patellofemoral joint radiography auxiliary device (PJR)
PJR
Measure
used

\begin{tabular}{|c|c|c|c|c|c|c|c|}
\hline Parameter & \multirow[t]{2}{*}{$70^{\circ}$} & \multirow[t]{2}{*}{$60^{\circ}$} & \multirow[t]{2}{*}{$50^{\circ}$} & \multirow[t]{2}{*}{$40^{\circ}$} & \multirow[t]{2}{*}{$30^{\circ}$} & \multirow[t]{2}{*}{$20^{\circ}$} & \multirow[t]{2}{*}{$\begin{array}{l}p- \\
\text { value }\end{array}$} \\
\hline $\begin{array}{l}\text { Degree of } \\
\text { flexion }\end{array}$ & & & & & & & \\
\hline $\begin{array}{l}\text { Patellar } \\
\text { angle }\end{array}$ & $18^{\circ}$ & $15^{\circ}$ & $12^{\circ}$ & $9^{\circ}$ & $6^{\circ}$ & $4^{\circ}$ & - \\
\hline $\begin{array}{l}\text { X-ray tube } \\
\text { angle }\end{array}$ & $108^{\circ}$ & $105^{\circ}$ & $102^{\circ}$ & $99^{\circ}$ & $96^{\circ}$ & $94^{\circ}$ & - \\
\hline $\begin{array}{l}\text { Detector } \\
\text { angle }\end{array}$ & $72^{\circ}$ & $75^{\circ}$ & $78^{\circ}$ & $81^{\circ}$ & $84^{\circ}$ & $86^{\circ}$ & - \\
\hline a) DMLP & $\begin{array}{l}11.27 \pm \\
0.16\end{array}$ & $\begin{array}{l}10.69 \pm \\
0.23\end{array}$ & $\begin{array}{l}10.24 \pm \\
0.23\end{array}$ & $\begin{array}{l}9.97 \pm \\
0.15\end{array}$ & $\begin{array}{l}9.95 \pm \\
0.1\end{array}$ & $9.95 \pm 0.1$ & 0.001 \\
\hline b) DPFG & $\begin{array}{l}11.16 \pm \\
0.71\end{array}$ & $\begin{array}{l}11.59 \pm \\
0.68\end{array}$ & $\begin{array}{l}9.41 \pm \\
0.36\end{array}$ & $\begin{array}{l}12.35 \pm \\
0.67\end{array}$ & $\begin{array}{l}10.1 \pm \\
0.53\end{array}$ & $8.28 \pm 0.65$ & 0.001 \\
\hline c) DFGT & $\begin{array}{l}-4.14 \pm \\
0.16\end{array}$ & $\begin{array}{l}-5.47 \pm \\
0.2\end{array}$ & $\begin{array}{l}-5.75 \pm \\
0.17\end{array}$ & $\begin{array}{l}-0.37 \pm \\
0.36\end{array}$ & $\begin{array}{l}2.5 \pm \\
0.32\end{array}$ & $4.87 \pm 0.26$ & 0.001 \\
\hline
\end{tabular}

DMLP = The distance between the line connecting the medial and lateral sides of the patella and the lowest point of the median ridge of the patella, which was measured to evaluate patellar inclination

DPFG $=$ The patellofemoral joint space distance

DFGT = The distance between the femoral trochlear groove and the tibial tuberosity, which was measured to evaluate the degree of overlap between the two bones

The difference in the DMLP values between knee flexion by $20^{\circ}$ degree, $160^{\circ}$ angle of the long axis of the femur and lower leg and knee flexion by $40^{\circ}$ degree, $140^{\circ}$ angle of the long axis of the femur and lower leg was not significantly different at $0.24 \%(p=1.000)$. In the DPFG evaluation, the largest patellofemoral joint spacing was when the knee was bent at $40^{\circ}$ degree, the angle between the long axis of the femur and the lower leg was set to $140^{\circ}$. When the knee was bent at $20^{\circ}$ degree, the angle between the long axis of the femur and the lower leg was $160^{\circ}$, the change in the DPFG value was not significant at $32.94 \%$ ( $p=$ 1.000). In the DFGT evaluation, the most consistent value between the femoral trochlear groove and the tibial tuberosity was when the knee was bent at $40^{\circ}$ degree, the angle between the long axis of the femur and the lower leg was set to $140^{\circ}$. When the knee was bent at $20^{\circ}$ degree, the angle between the long axis of the femur and the lower leg was $160^{\circ}$, the change in the DFGT value was significantly different at $107.56 \%(p<0.05)($ Table 2$)$. 
Table 2

Comparison of PJR images taken at $140^{\circ}$ and $160^{\circ}$ of knee flexion angles

\begin{tabular}{|llll|}
\hline Comparison between two groups & Measure & & \\
Parameter & $40^{\circ}$ & $20^{\circ}$ & $p$-value \\
\hline Pegree of flexion & & & \\
\hline X-ray tube angle & $9^{\circ}$ & $4^{\circ}$ & - \\
\hline Detector angle & $99^{\circ}$ & $94^{\circ}$ & - \\
\hline a) DMLP & $81^{\circ}$ & $86^{\circ}$ & - \\
\hline b) DPFG & $9.97 \pm 0.15$ & $9.95 \pm 0.1$ & 1.000 \\
\hline c) DFGT & $12.35 \pm 0.68$ & $8.28 \pm 0.65$ & 0.001 \\
\hline
\end{tabular}

\subsection{Comparison of PJR with the Settegast and Merchant radiography methods}

The measured values using PJR with the phantom's knee bent at $40^{\circ}$ degree and the angle between the long axis of the femur and the long axis of the lower leg set at $140^{\circ}$ were compared with the values measured by the Settegast and Merchant methods. The results of comparisons of all measurements are shown in Table 3 and Fig. 6 b.

Table 3

Comparison of the measured values by PJR with those of the Merchant and Settegast methods

\begin{tabular}{|lllll|}
\hline Comparison among three groups & \multicolumn{4}{c}{ Measure } \\
\hline Parameter & PJR & Merchant & Settegast & $p$-value \\
\hline Degree of flexion & $40^{\circ}$ & $45^{\circ}$ & $105^{\circ}$ & \\
\hline Patellar angle & $9^{\circ}$ & $13^{\circ}$ & $14.5^{\circ}$ & - \\
\hline X-ray tube angle & $99^{\circ}$ & $60^{\circ}$ & $15^{\circ}$ & - \\
\hline Detector angle & $81^{\circ}$ & $45^{\circ}$ & $0^{\circ}$ & - \\
\hline a) DMLP & $9.97 \pm 0.15$ & $10.57 \pm 0.47$ & $9.40 \pm 0.47$ & 0.001 \\
\hline b) DPFG & $12.35 \pm 0.68$ & $10.55 \pm 0.43$ & $8.54 \pm 0.65$ & 0.001 \\
\hline c) DFGT & $-0.37 \pm 0.36$ & $3.93 \pm 0.23$ & $5.42 \pm 0.49$ & 0.001 \\
\hline
\end{tabular}

In the DMLP evaluation, the smallest patellar inclination and best display of the half lateral image of the patella was with the Settegast method, followed by PJR and the Merchant method. The measured DMLP values significantly differed by $5.76 \%$ between the Settegast method and PJR; by $5.62 \%$ between PJR and 
the Merchant methods $(p=0.001)$. In the DPFG evaluation, the largest patellofemoral joint spacing was seen with PJR, followed by the Merchant method and the Settegast method. The measured DPFG values significantly differed by $14.54 \%$ between PJR and the Merchant method; by $19.01 \%$ between the Settegast and Merchant methods $(p=0.001)$. In the DFGT evaluation, the distance between the femoral trochlear groove and the tibial tuberosity was the most consistent with PJR, followed by the Merchant method and the Settegast method. The measured DFGT values significantly differed by $109.41 \%$ between PJR and the Merchant method; by $27.75 \%$ between the Settegast and Merchant methods $(p=0.001)$.

\section{Discussion}

This study was conducted to find the most suitable tangential axial radiography method for the patellar and patellofemoral joints by comparing PJR with the conventional radiographic methods. Among the radiographic conditions using PJR weres compared with the conventional imaging methods of Settegast and Merchant. In the DMLP evaluation, when the knee of the phantom was bent at $70^{\circ}$ to $20^{\circ}$ at $10^{\circ}$ intervals using PJR, the DMLP value decreased as the angle of flexion was increased. This implied that the inclination or tilt of the patella decreased when the knee was extended than when the knee was flexed and that the half lateral image of the patella was more accurately displayed with the former. Laurin method with a knee flexion angle of $20^{\circ}$ had the smallest inclination of the patella and the half lateral image of the patella showed the best results. But, based on the DFGT results, as the value representing the distance between the femoral trochlear groove and the tibial tuberosity increased to a positive value, the tibial tuberosity invaded the patellofemoral joint area and resulted in narrowing of the patellofemoral joint space. On the other hand, as the distance between the femoral trochlear groove and the tibial tuberosity was reduced to a negative value, the inclination of the patella became larger. In addition, among the radiographic conditions using PJR, $20^{\circ}$ knee flexion, which is similar to that in the Laurin method, and $160^{\circ}$ angle of the long axis of the femur to the long axis of the lower leg resulted in the largest invasion of the tibial tuberosity to the patellofemoral joint and the narrowest patellofemoral joint spacing (Fig. 6a). Although the Settegast method gave the smallest inclination of the patella on imaging, it required the largest knee bending angle and may cause further discomfort to a patient with knee pain. When the distance between the femoral trochlear groove and the tibial tuberosity was the largest and the tibial surface invaded the patellofemoral joint space, the resulting image had the narrowest joint spacing. The reason for the result of the smallest inclination of the patella with the Settegast method than with the Merchant and PJR methods was thought to be close contact of the patella with the detector in the prone position. The object to image receptor distance (OID) between the patella and the detector was the target area for radiographic imaging. If the OID was short, distortion in the radiographic image was reduced. On the other hand, if the OID was increased, the image was enlarged and had a degraded quality, resulting in blurring and low contrast [13-15]. The Merchant method showed the greatest patellar inclination, and the overlap between the patellofemoral joint space and the femoral trochlear groove and the tibial tuberosity was not as good as the PJR method, but better than the Settegast method. With the results of the DMLP, DPFG, and DFGT evaluations taken together, $40^{\circ}$ knee flexion with $140^{\circ}$ angle between the long axis of 
the femur and the long axis of the lower leg was the most beneficial radiographic condition using PJR (Fig. 6b).

Tangential axial radiography must be performed in order to detect patellar fracture and injury and patellofemoral joint stenosis and wear and to determine the correlation between the femur and tibia. However, conventional radiography methods have several disadvantages. First, although the Settegast and Hughston methods are relatively frequent in the clinical setting because of the relatively short procedure time, the required prone position and knee flexion may be difficult in patients complaining of pain from patellar fracture or dislocation $[3,16-18]$. In the prone position, the patellar area comes into contact with the examination table and a load is applied; this may worsen the pain in the area near the knee and should be avoided $[3,17]$. Second, the Laurin and Merchant methods are radiographic methods that can be used to diagnose patellofemoral joint disease in a sitting or supine position without the need to prone. The Laurin method mainly measures the lateral patellofemoral angle and checks whether patellar is normally open to the outside. The Laurin method was said to require the smallest bending angle of the knee and was the closest to the actual structure of the patellar [10,11]. However, as the knee bending angle decreases, the distance between the femoral trochlear groove and the tibial tuberosity increases, the tibial surface invades the patellofemoral joint space, and the gap narrows. Therefore, this is not suitable for viewing minute damages to the patellofemoral joint. Moreover, the Laurin method necessitates postural instability, because the patient must bend the knee in a sitting position, directly hold the detector, and perform radiography. In addition, in a sitting position, special care is required to avoid radiation exposure of areas other than the patellofemoral joint [3].

Most of the existing studies on patellofemoral joint observation determined patellar dislocation and subluxation by measuring the congruence and sulcus angles $[15,19,20]$. To measure this in the Merchant method, the long axis of the femur must be parallel to the surface of the examination table using an auxiliary device. In the Merchant method, each knee is radiographed separately. When both legs are shot simultaneously, one leg may not be fixed and the knee may be adducted or abducted; these may increase the matching angle and distort the image [19]. In addition, when the distance from the source is doubled, the radiation intensity is proportional to the inverse square of the distance, where the radiation level per unit area decreases to $1 / 4$ [22]. In the case of similar source to image receptor distance (SID), as the distance from the source of the X-ray tube to the object part (SOD) increases, the entrance surface dose decreases. Conversely, as the OID becomes closer, enlargement of the image is prevented $[13,23]$. The set OID was about $30 \mathrm{~cm}$ for the Merchant method and about $20 \mathrm{~cm}$ for PJR (Fig. 7). In this research, because the tangential axial radiography method using PJR had 10-cm longer SOD and 10-cm shorter OID, compared with those by the Merchant method, the latter will create more exposure to radiation doses. Comparison of radiation doses in tangential axial radiography of the patellofemoral joint requires more in-depth experiments. Nevertheless, radiographic imaging using PJR may be a good means of solving some of the shortcomings of the conventional radiographic methods. Specifically, PJR may allow patients to comfortably undergo radiographic imaging in a supine position and may enable a stable position to prevent shaking or distortion of the image at the target site. Compared with the conventional radiographic methods, PJR showed radiographic images in which the patellofemoral joint space was 
larger, the gap between the trochlear groove and the tibial tuberosity was consistent, and the half lateral image of the patella was clearly shown (Fig. 8).

One limitation of this study was that comparison of different patellofemoral joints among humans was not possible. However, by performing several patellofemoral joint radiography imaging on the phantom knee joint, we were able to quantify the most optimal patellar and patellofemoral joint shapes. In the future, studies that measure the shape of several patellofemoral joints in humans are needed.

\section{Conclusions}

We propose the use of PJR for tangential axial radiography of the patellar and patellofemoral joints. PJR may provide convenience to patients and images of high diagnostic value. We look forward to its further use in the clinical field in the future.

\section{Declarations}

Author contributions All authors contributed equally.

Funding This research did not receive any specific grant from funding agencies in the public, commercial, or not-for-profit sectors.

Data availability All data relevant to this article can be made available upon request.

\section{Declarations}

Conflict of interest The authors have no relevant financial or non-financial interests to disclose.

Ethics approval This study does not require ethical approval.

Code availability The source code, demo, and early evaluation results can be provided as needed.

\section{References}

1. Dixit S, Difiori JP, Burton M, Mines B (2007) Management of patellofemoral pain syndrome. Am Fam Phys 75(2):194-202. PMID 17263214

2. Nagamine R, Otani T, White SE, McCarthy DS, Whiteside LA (1995) Patellar tracking measurement in the normal knee. J Orthop Res 13(1):115-122. https://doi.org/10.1002/jor.1100130117

3. Rhee DB, Seo SJ, Choi HW, Lee SH, Kim JK (2020) Development and use of supporting device for patellar X-ray imaging. J Biomed Eng Res 41(4):165-171. https://doi.org/10.9718/JBER.2020.41.4.165

4. Brattstroem $H$ (1964) Shape of the intercondylar groove normally and in recurrent dislocation of patella: a clinical and x-ray anatomical investigation. Acta Orthop ScandSuppl. 35:sup68:1-148. https://doi.org/10.3109/ort.1964.35.suppl-68.01 
5. McAlindon TE, Cooper C, Kirwan JR, Dieppe PA (1993) Determinants of disability in osteoarthritis of the knee. Ann Rheum Dis 52(4):258-262. https://doi.org/10.1136/ard.52.4.258

6. Hobbs DL (2005) Tangential projection of the patella. Radiol Technol 77(1):20-21. PMID 16218017

7. Ficat RP, Philippe J, Hungerford DS (1979) Chondromalacia patellae: a system of classification. Clin Orthop Relat Res 144(144):55-62. https://doi.org/10.1097/00003086-197910000-00011

8. Davies AP, Bayer J, Owen-Johnson S, Shepstone L, Darrah C, GlasgowM M, Donell ST (2004) The Optimum Knee Flexion Angle for Skyline Radiography Is Thirty Degrees. Clin Orthop Relat Res 423:166-171. https://doi.org/10.1097/01.blo.0000129160.07965.e7

9. Ko YW, Joo YC, Kim MS, Go YR (2020) The assessment of tube incidence angle for minimizing the patellofemoral joint overlap distance in merchant View. J Radiol Sci Technol 43(3):161-167. https://doi.org/10.17946/JRST.2020.43.3.161

10. Laurin CA, Dussault R, Levesque HP (1979) The tangential x-ray investigation of the patellofemoral joint: $x$-ray technique, diagnostic criteria and their interpretation. Clin Orthop Relat Res 144(144):1626. https://doi.org/10.1097/00003086-197910000-00004

11. Laurin CA, Lévesque HP, Dussault R, Labelle H, Peides JP (1978) The abnormal lateral patellofemoral angle: a diagnostic roentgenographic sign of recurrent patellar subluxation. J Bone Joint Surg Am 60(1):55-60. https://doi.org/10.2106/00004623-197860010-00007

12. Merchant AC, Mercer RL, Jacobsen RH, Cool CR (1974) Roentgenographic analysis of patellofemoral congruence. J Bone Joint Surg Am 56(7):1391-1396. https://doi.org/10.2106/00004623197456070-00007

13. Holliday M, Steward A (2021) Pre-operative templating for total hip arthroplasty: how does radiographic technique and calibration marker placement affect image magnification. J Med Radiat Sci 15. https://doi.org/10.1002/jmrs.461

14. Schueler BA (2000) The AAPM/RSNA physics tutorial for residents: general overview of fluoroscopic imaging. RadioGraphics 20(4):1115-1126. https://doi.org/10.1148/radiographics.20.4.g00jl301115

15. Pittayapat $P$, Thevissen P, Fieuws $S$, Jacobs R, Willems G (2010) Forensic oral imaging quality of hand-held dental X-ray devices: comparison of two image receptors and two devices. Forensic Sci Int 194(1-3):20-27. https://doi.org/10.1016/j.forsciint.2009.09.024

16. Hughston JC (1968) Subluxation of the patella. J Bone Joint Surg Am 50(5):1003-1026. https://doi.org/10.2106/00004623-196850050-00014

17. Seoung YH (2013) Usefulness evaluation of merchant auxiliary equipment of body type changing suitable for X-ray table integral type. J Korea Acad-Ind Coop Soc 14(6):2773-2779. https://doi.org/10.5762/KAIS.2013.14.6.2773

18. Fulkerson JP (2002) Diagnosis and treatment of patients with patellofemoral pain. Am J Sports Med 30(3):447-456. https://doi.org/10.1177/03635465020300032501

19. Chung YK, Lee KB, Young WK (1986) A clinical study of traumatic dislocation of the knee joint: analysis of 7 cases. J Korean Orthop Assoc 21(4):703-708. https://doi.org/10.4055/jkoa.1986.21.4.703 
20. Kim HJ, Joo YC, Choi JH, Lim WT (2019) Assessment of Congruence Angle according to the Central X-ray in the Merchant View of patellofemoral Joint. J Radiol Sci Technol 42(6):423-428. https://doi.org/10.17946/JRST.2019.42.6.423

21. Aglietti P, Insall JN, Cerulli G (1983) Patellar pain and incongruence. I: Measurements of incongruence. Clin Orthop Relat Res 176:217-224. PMID 6851329

22. Hoskins JK, Newman RD, Spero R, Schultz J (1985) Experimental tests of the gravitational inversesquare law for mass separations from 2 to $105 \mathrm{~cm}$. Phys Rev D Part Fields 32(12):3084-3095. https://doi.org/10.1103/physrevd.32.3084

23. Sharma R, Sharma SD, Pawar S, Chaubey A, Kantharia S, Babu DA (2015) Radiation dose to patients from X-ray radiographic examinations using computed radiography imaging system. J Med Phys 40(1):29-37. https://doi.org/10.4103/0971-6203.152244

\section{Figures}

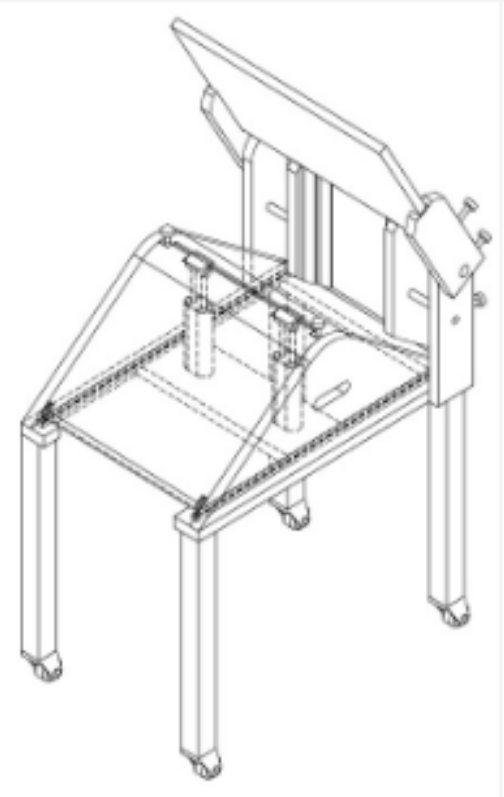

(a)

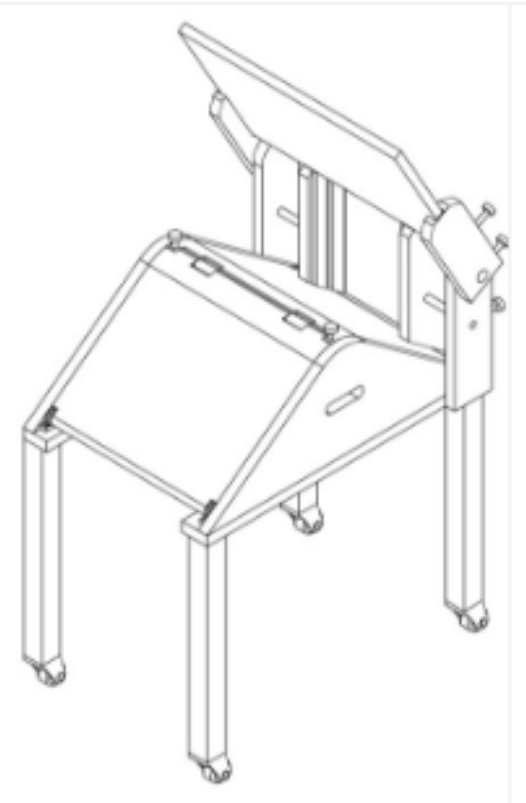

(b)

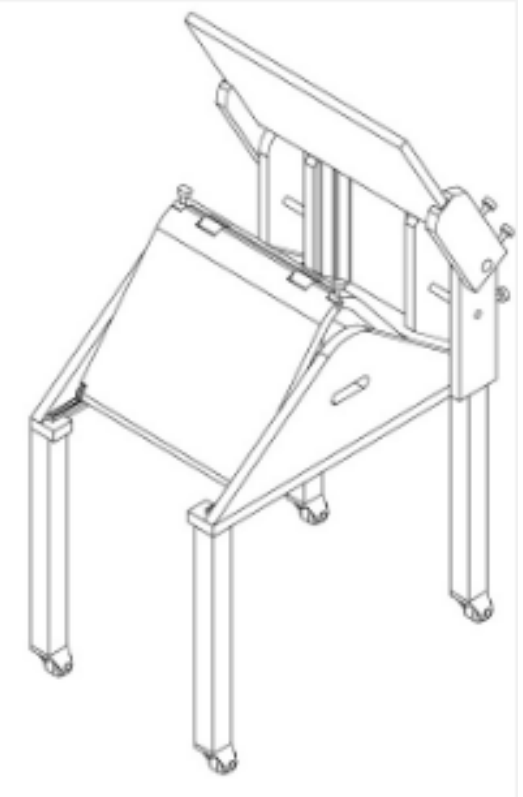

(c)

\section{Figure 1}

Development of patellofemoral joint radiography auxiliary device (PJR) (a) Structure of the PJR (b) The form of widening the angle of the PJR (c) The form of narrowing the angle of the PJR 


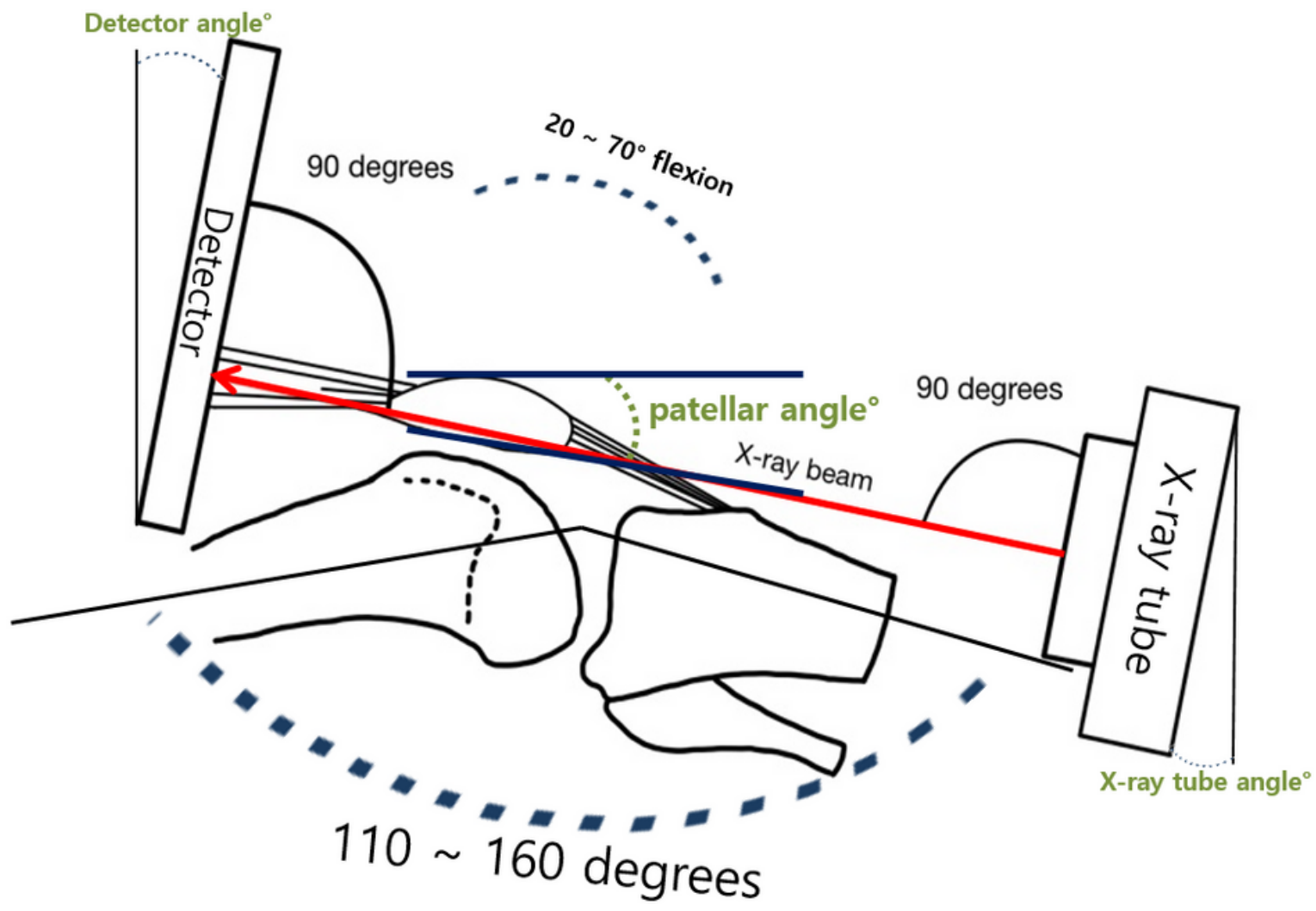

Figure 2

Set the X-ray tube and detector angles to be perpendicular to the angle of the patella 


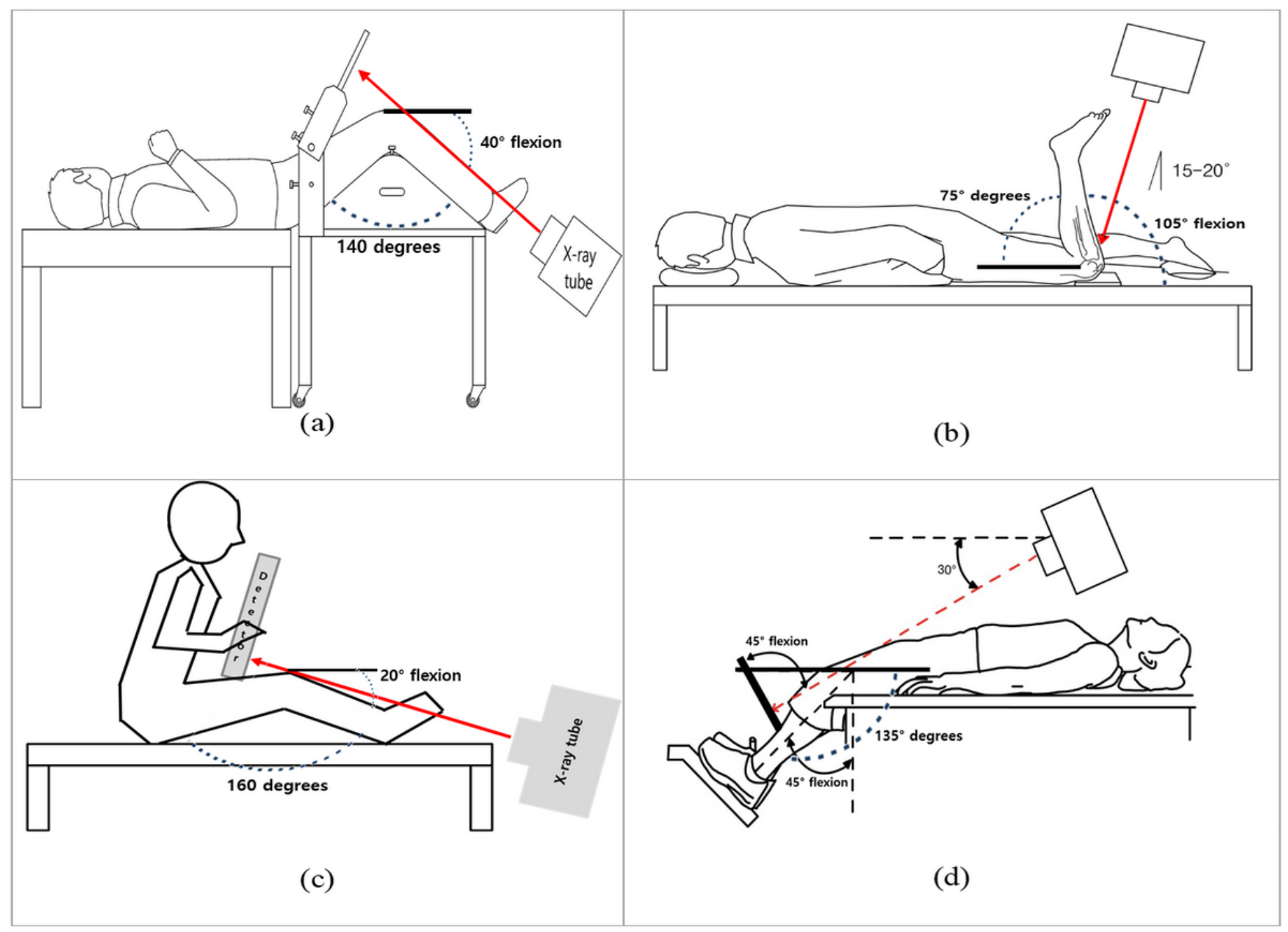

\section{Figure 3}

Patellar tangential axial radiography imaging (a) Patellar tangential axial projection method using the PJR (b) Settegast method (c) Laurin method (d) Merchant method 

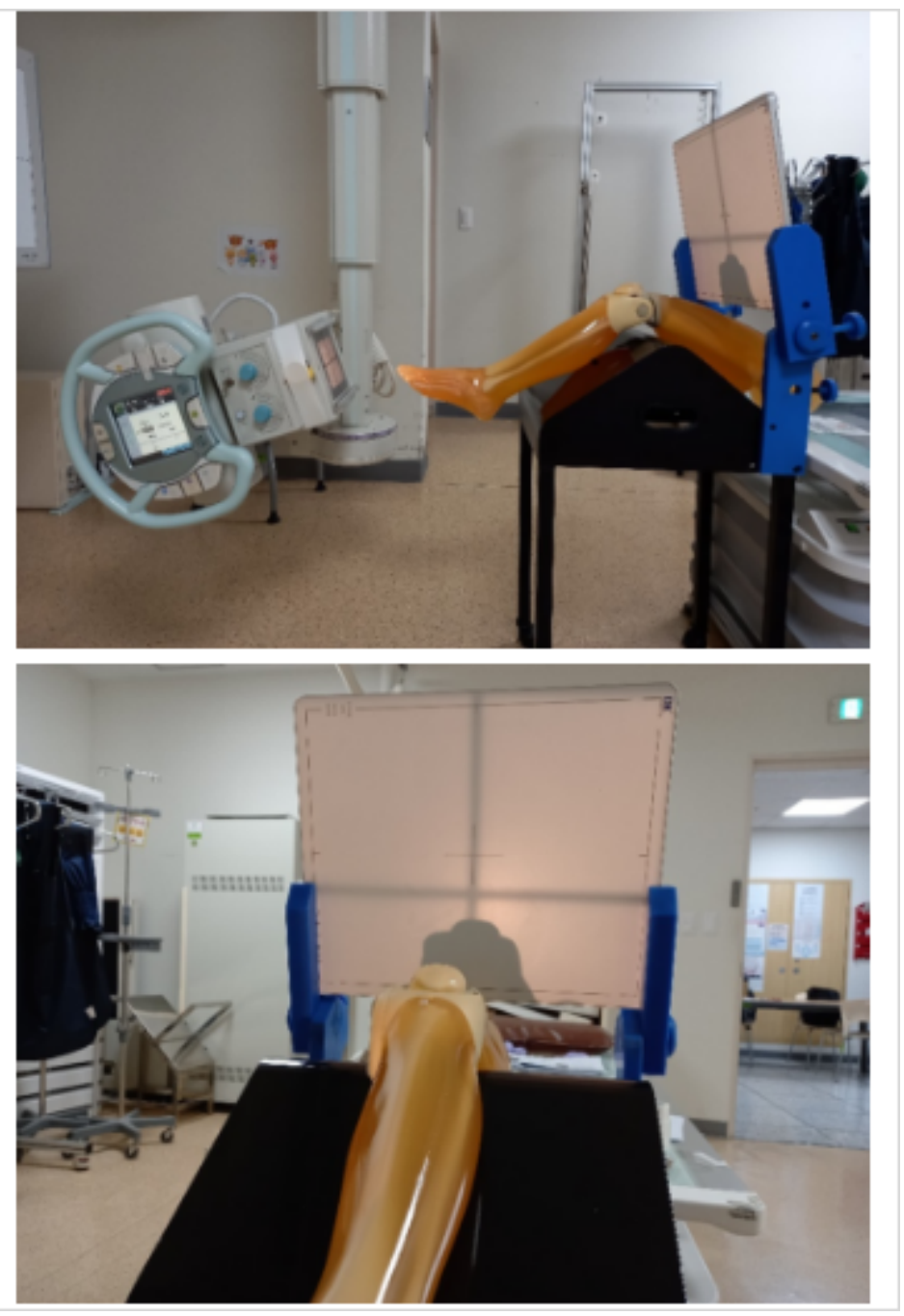

\section{Figure 4}

A phantom was mounted on the developed body of the PJR, and radiographs were taken in the tangential axial projection 


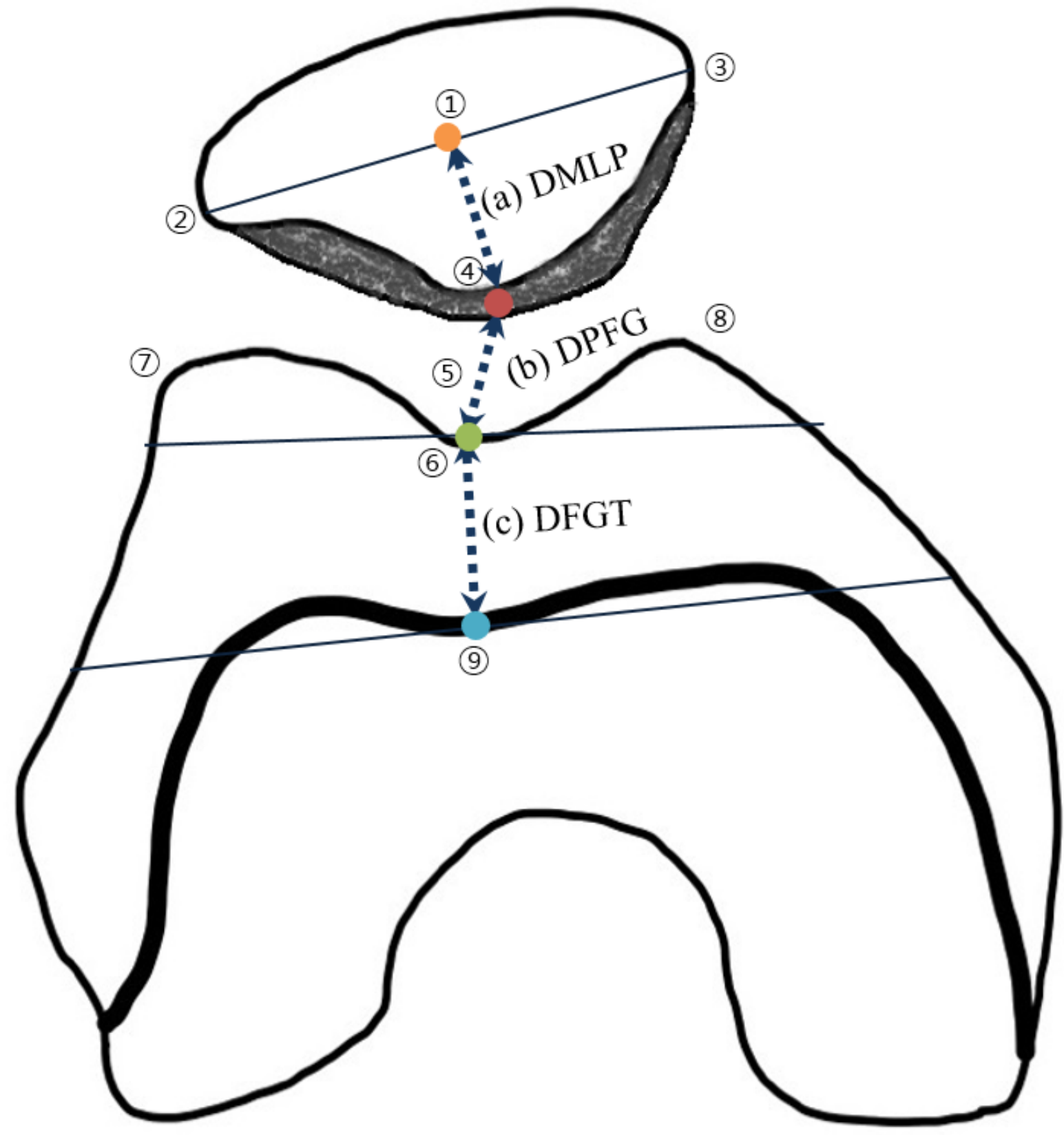

Figure 5

Measurement items ( patella, lateral facet of patella, medial facet of patella, The lowest point of the median ridge of the patella, patellofemoral joint space, femoral trochlear groove, lateral trochlear ridge, medial trochlear ridge, tibial tuberosity) (a) DMLP: The distance between the line connecting the medial and lateral sides of the patella and the lowest point of the median ridge of the patella (b) DPFG: Distance of the patellofemoral joint space distance (c) DFGT: Distance between the femoral trochlear groove and the tibial tuberosity 


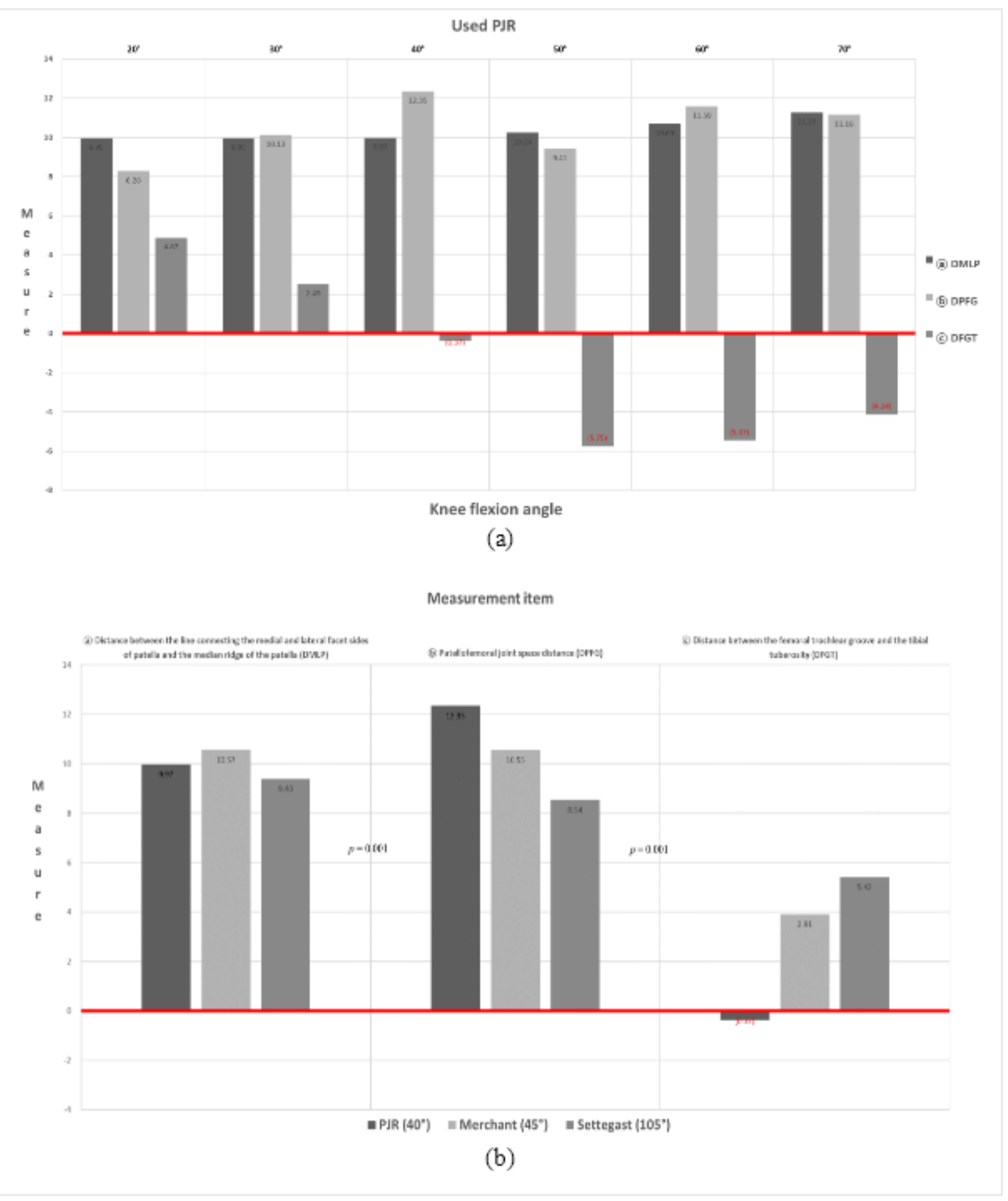

\section{Figure 6}

(a) Results of taking radiographic images at $160^{\circ}$ to $110^{\circ}$ using PJR and changing the knee flexion angle at $10^{\circ}$, (b) A graph comparing the measurement results among PJR, Merchant method, and Settegast method 


\section{X-ray tube}

\section{Source}

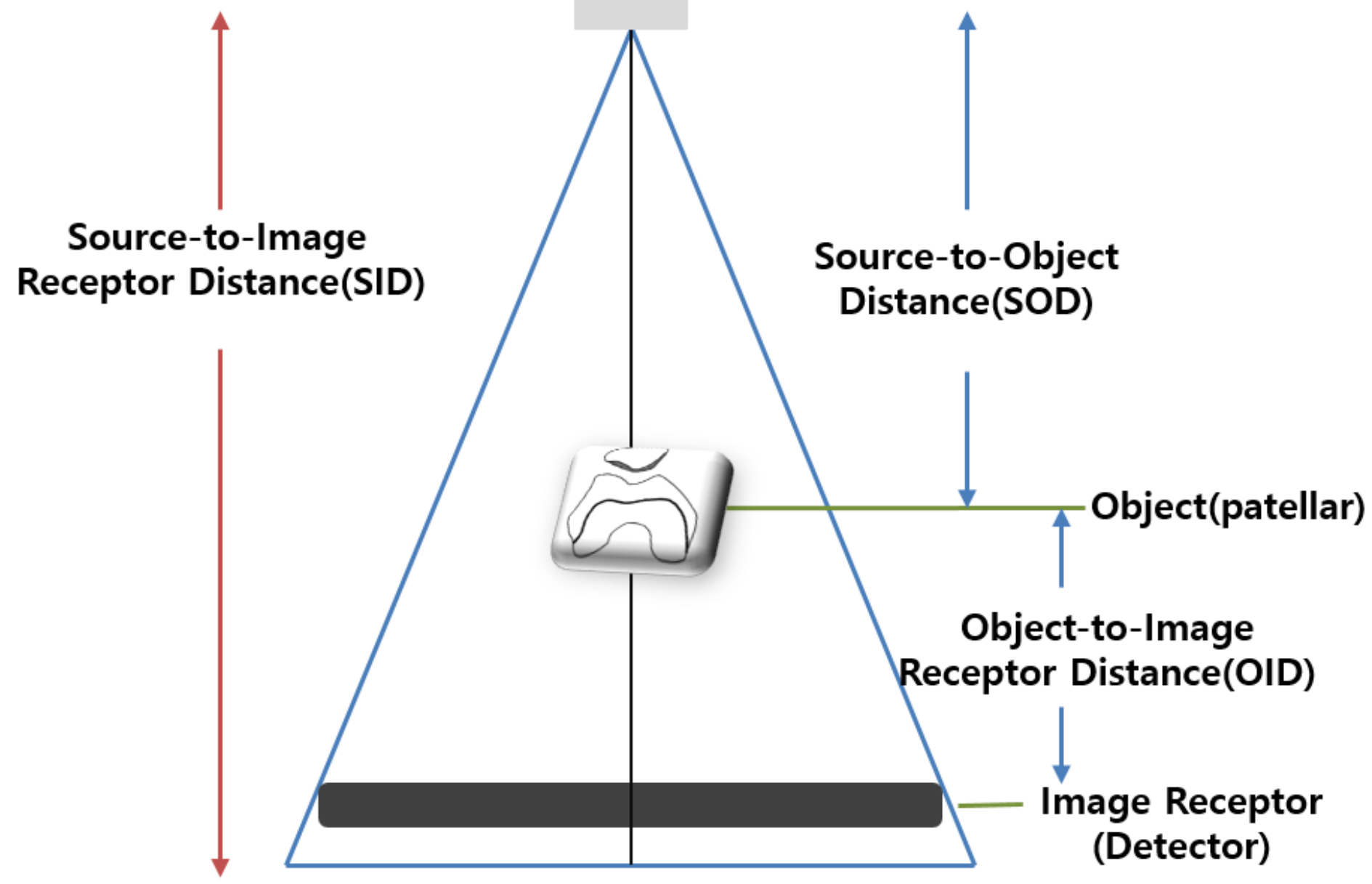

Figure 7

Fundamental concepts of source to image receptor distance (SID), source to object distance (SOD) and object to image receptor distance (OID) 


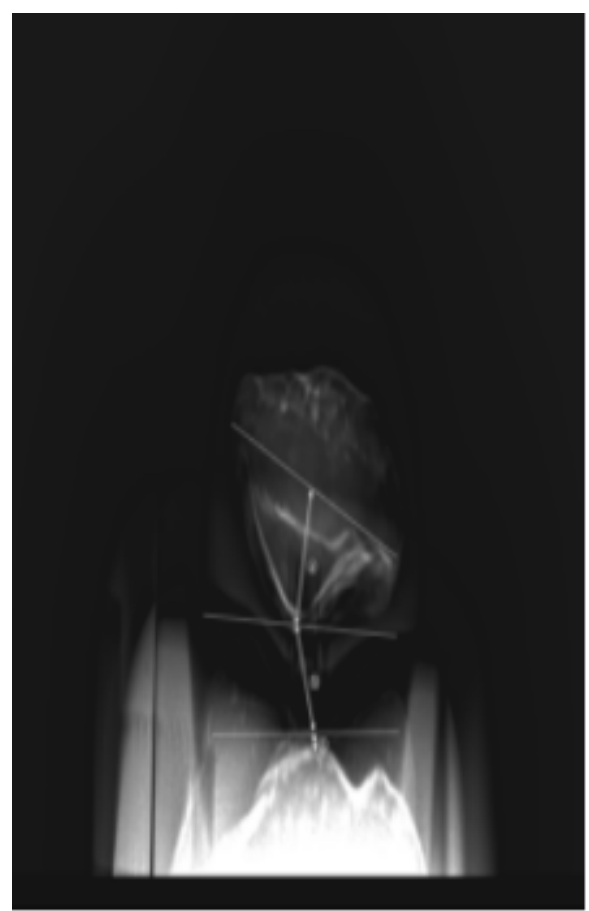

(a)

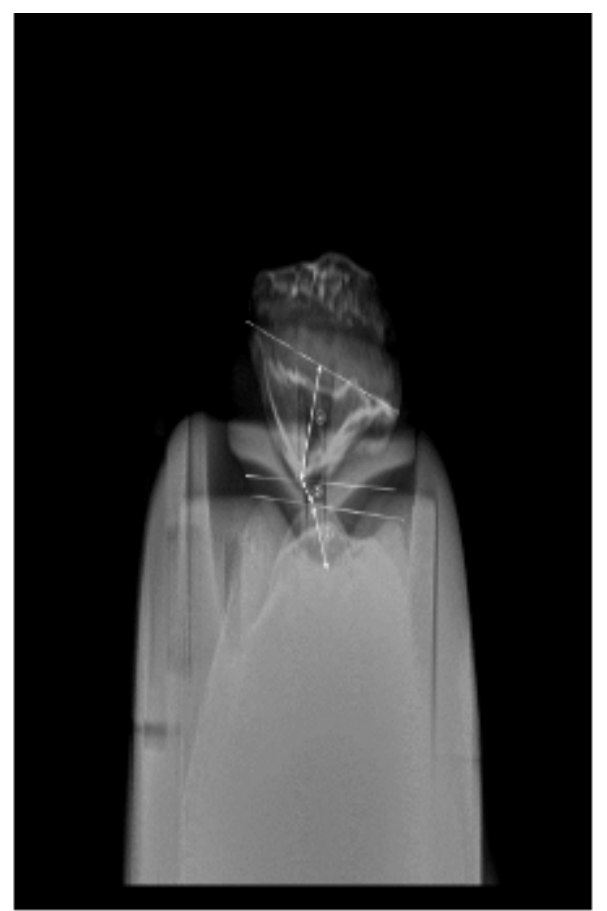

(b)

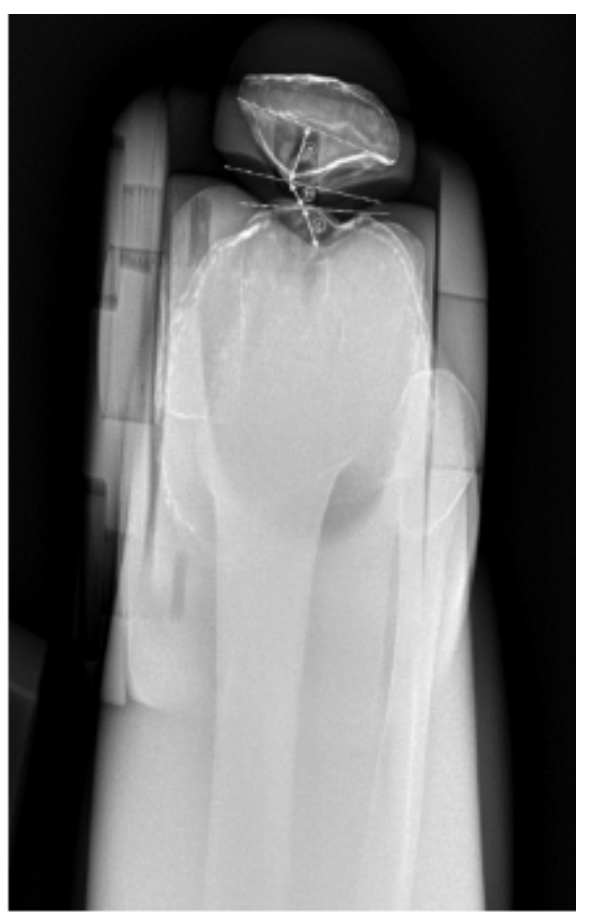

(c)

\section{Figure 8}

Phantom X-ray images taken by each method ( DMLP, DPFG, DFGT) (a) Method using PJR (b) Merchant method (c) Settegast method 